\title{
Chemical Composition and Insecticidal Potential of Pulicaria incisa (Lam) Essential Oil from Moroccan Plant Against Sitophilus oryzae (L.) and Tribolium castaneum (Herbst.)
}

\author{
Hanane Lougraimzi ${ }^{1 *}{ }^{\mathbb{D}}$, Redouane Benhima ${ }^{2 \mathbb{C}}$, Rajaa Kholssi ${ }^{3(\mathbb{D}}$, Ebich Fatima ${ }^{4 \mathbb{D}}$, El Hassan \\ Achbani ${ }^{5(\mathbb{D})}$, Mohamed Fadli ${ }^{1}$ (D)
}

1 Laboratory of Nutrition, Health and Environment, Department of Biology, Faculty of Sciences, Ibn Tofail University, B.P. 242 Kenitra, Morocco

2 Laboratory of Green Biotechnology, Moroccan Foundation for Advanced Science, Innovation and Research. Rabat Design Center, Madinat Al Irfan, Rabat, Morocco

3 Laboratory of Edaphology, Faculty of Sciences, Department of Chemistry, Faculty of Sciences, University of Burgos, 09001 Burgos, Spain

4 Laboratory of Agroresources and Process Engineering, Faculty of Sciences, University Ibn Tofail, B.P 242 Kenitra, Morocco

5 Laboratory of Phytobacteriology and Biocontrol, National Institute of Agronomic Research, P7058 Meknes, Morocco

* Correspondence: hanane.lougraimzi@uit.ac.ma;

Scopus Author ID 57204115268

Received: 21.03.2021; Revised: 15.05.2021; Accepted: 20.05.2021; Published: 18.06.2021

\begin{abstract}
Pulicaria incisa (Lam) is a wild-growing plant in Morocco and has been traditionally used by farmers to control pests of stored grains. The present study was conducted to investigate the chemical composition and insecticidal effect of the essential oil of P. incisa against Sitophilus oryzae (L.) and Tribolium castaneum (Herbst.) by different methods (contact, fumigation and ingestion). The aerial parts of the plant were subjected to hydrodistillation using a Clevenger-type apparatus. The essential oil composition was analyzed by gas chromatography (GC) and mass spectrophotometry (MS). Sixtysix compounds representing $89.4 \%$ of total oil were identified. The main components were $\alpha$-Ocimene $(15.17 \%), \tau$-Cadinol (6.79\%), $\alpha$-Cadinol (4.51\%), Alloaromadendrene (4.45\%) $\delta$-Cadinene, $(+)$ (4.13\%). The repellant toxicity test results revealed a higher repellency effect in $S$. oryzae than $T$. castaneum. Lethal concentration (LC50), varied between $15.49-1.73 \mu \mathrm{L} / \mathrm{cm}^{2}$ and $20.89-2.29 \mu \mathrm{L} / \mathrm{cm}^{2}$ respectively. In the fumigation test, adults of $S$. oryzae and T. castaneum were sensitive to the essential oil with LC50 values varying between $16.21-2.08$ and $18.62-2.51 \mu \mathrm{L} / \mathrm{L}$ air. In addition, experiments have shown that the ingestion method is the most toxic towards both insects with LC50 values of the order of $12.59-1.51 \mu \mathrm{L} / \mathrm{g}$ for $S$. oryzae and $14.12-2.39 \mu \mathrm{L} / \mathrm{g}$ for $T$. castaneum. While the lethal time (LT50) values decreased with increasing essential oil concentration, and in all cases, the increased susceptibility of both insects was directly associated with oil concentration and exposure time. This study aims to valorize medicinal and aromatic plants of the Moroccan flora in order to find novel bioinsecticidal products. Furthermore, the study reports for the first time the insecticidal activity of $P$. incisa against adults S. oryzae and T. castaneum.
\end{abstract}

Keywords: essential oil; $\mathrm{LC}_{50} ; \mathrm{LT}_{50}$; toxicity; insecticidal potential.

(C) 2021 by the authors. This article is an open-access article distributed under the terms and conditions of the Creative Commons Attribution (CC BY) license (https://creativecommons.org/licenses/by/4.0/). 


\section{Introduction}

The rice weevil, Sitophilus oryzae (L.) (Coleoptera: Curculionidae), and the rust-red flour beetle, Tribolium castaneum (Herbst) (Coleoptera: Tenebrionidae), are among the most widespread and destructive stored product pests throughout the world. These two species can cause the total loss of an entire stock [1,2]. With over 60 percent of the African continent's population in rural areas and dependent on smallholder or family farming, the risk from the COVID-19 pandemic to food supply chains, market access, and nutrition is high [3]. In Morocco, the regular supply of the local market with cereals, particularly soft wheat, is a strategic issue for the country's food security. Therefore, the country to prioritize the reduction of post-harvest losses through the launch of a project in partnership with FAO, which aims to identify post-harvest losses and wastage of major agricultural products, to understand the underlying causes and factors better and guide to develop a national strategy and action plan to reduce these losses.

In the past two decades, the control of losses attributed to insects in stored food products relies heavily on the use of synthetic insecticides [4]. But some of them are banned, like phosphine (synthetic fumigant), which has been the method the most widespread and best known in Morocco and around the world [5,6]. Due to serious dangers to warm-blooded animals and the environment, as well as problems of persistent toxicity in cereals, the search for ecologically safe methods to control insect pests of stored food products is essential $[7,8,9]$. Therefore, plants offer an alternative source of insect control agents because they contain a range of bioactive chemicals, many of which are selective and have little or no harmful effect on non-target organisms and the environment $[10,11,12]$. In several countries, essential oils (EOs) and powders from aromatic plants are traditionally used through fumigant or contact action to protect grains against storage pests $[13,14,15]$. They are characterized by a mixture of complex, volatile organic compounds produced by different plants from different families $[16,17,18]$. EOs of aromatic plants have been reported to possess a wide range of biological properties, including insecticidal activity $[19,20]$. Among these plants are the Asteraceae family, which are flowering plants growing in Saharan zones. These plants have a pleasant aromatic odor due to the presence of EO in the different parts of the plants. Numerous scientific works published in the literature have demonstrated various biological activities of certain Pulicaria species; among them, Mohammed et al. [21] report that the EO of extracted leafy stems Pulicaria undulata reveals an antioxidant antiproliferative and d-enzymatic inhibition. Zardi-Bergaoui et al. [22] show the antioxidant effect, antibacterial, anti-tyrosinase, and cytotoxic activities of EO of the Tunisian plant Pulicaria vulgaris. While, El-Sabagh et al. [23] studied the metabolite profiles of Pulicaria crispa and Pulicaria incisa, which revealed antioxidant and hepatoprotective effects only in relation to its bioactive metabolites. Likewise, El-Shahaby et al. [24] have demonstrated the antioxidant activity and the antimicrobial potential of extracts of Pulicaria incisa, which can be attributed to its richness in active metabolites. Other researchers have also reported insecticidal properties of the genus Pulicaria $[25,26]$.

In this regard, the present study aims to evaluate the insecticidal effect of $P$. incisa EO in vitro toxicity of EO of this Moroccan aromatic plant was tested against adults of $S$. oryzae and $T$. castaneum, to find the most effective method (repellency/fumigation/ingestion) to achieve the highest insecticidal activity against both insects. This study reports for the first time 
the insecticidal activity of $P$. incisa from Morocco, which farmers traditionally use to fight against pests of stored grains.

\section{Materials and Methods}

\subsection{Plant material.}

Aerial parts of Pulicaria incisa were collected in May and June 2016 in the Beni MellalKhenifra region, Morocco. The plant was identified at the Natural Substances and Biodiversity Laboratory of the Ibn Tofail University of Kenitra, Morocco, based on the document "Practical Flora of Morocco Volume 1, 2 and 3". The plant material was prepared and then dried in the shade at room temperature for four weeks.

\subsection{Extraction of essential oil.}

Pulicaria incisa was subjected to hydrodistillation for three hours (Clevenger). Plant material $P$. incisa was distilled with an additional phase briefly. The plant is cut and immersed in water and heated to boiling, after which the EO was evaporated with water vapor and finally collected after decantation. The distillate was isolated and dried in a Rota vapor to giving brownish-yellow oil. The extracted oil was stored away from air and light at a temperature of $4^{\circ} \mathrm{C}$

\subsection{Gas chromatography analysis.}

EO was characterized by gas chromatography (GC) (Agilent 7890A Series GC) coupled to mass spectrometry (MS) equipped with split/splitless injector, 123-BD11 column (15 m, $0.32 \mathrm{~mm}, 0.10 \mu \mathrm{m}$ ) and electron impact ionization. One $\mu \mathrm{L}$ of $1 \%$ (v:v) oil solubilized in chloroform was injected into the column by $2: 1$ split mode using helium as carrier gas at 4 $\mathrm{mL} / \mathrm{min}$. The ion source and quadruple temperatures were $230{ }^{\circ} \mathrm{C}$ and $150{ }^{\circ} \mathrm{C}$, respectively. The oven temperature program was started at $30{ }^{\circ} \mathrm{C}$ and maintained $2 \mathrm{~min}$, increased at 10 ${ }^{\circ} \mathrm{C} / \mathrm{min}$ until $80{ }^{\circ} \mathrm{C}$ and maintained $1 \mathrm{~min}$, then increased until $200{ }^{\circ} \mathrm{C}$ by $4{ }^{\circ} \mathrm{C} / \mathrm{min}$ and maintained $1 \mathrm{~min}$, then increased until $330^{\circ} \mathrm{C}$ at $25^{\circ} \mathrm{C} / \mathrm{min}$ and finally kept constant for $1 \mathrm{~min}$. The composition was determined from the peak areas. The identification was performed using NIST 2014 MS Library.

\subsection{Biological tests.}

Bioassays were performed to study the insecticidal effect of $P$. incisa $\mathrm{OE}$ on adults of $S$. oryzae and $T$. castaneum. Three EO toxicity tests were performed using three different methods: repellency, fumigation, and ingestion. The effectiveness of EO was compared to positive controls using powdered malathion (2\% Malathion) and aluminum phosphide fumigant, at a temperature of $27 \pm 1{ }^{\circ} \mathrm{C}$, relative humidity of $70 \pm 5 \%$.

\subsubsection{Repellency toxicity.}

The repellency test was conducted based on McDonald et al. [28] in a glass Petri dish ( $9 \mathrm{~cm}$ diameter, Whatman No.1 and $1 \mathrm{~cm}$ high), which contained a $9 \mathrm{~cm}$ filter paper. The EO was diluted in acetone to prepare different concentrations: 2, 5, 10 and $20 \mu \mathrm{L} / \mathrm{mL}$ of acetone, corresponding to concentrations of $0.031,0.079,0.157$ and $0.314 \mu \mathrm{L} / \mathrm{cm}^{2}$ respectively. One $\mathrm{mL}$ of each concentration was spread uniformly with a micropipette over a filter paper disc. The 
control only was treated with acetone. After completing the evaporation of the solvent (5 minutes), the treated filter papers were carefully placed in Petri dishes. Three replications were performed for each concentration of EO. Ten insects each of $S$. oryzae and $T$. castaneum species were introduced into each Petri dish, which was then closed immediately. Dead insects were counted daily for a period of 7 days.

\subsubsection{Fumigant toxicity.}

Fumigation with the EO of $P$. incisa was carried out in transparent, hermetic 1L plastic boxes as exposure chambers to test the toxicity of the EO against adults of $S$. oryzae and $T$. castaneum. The EO was spread over a $9 \mathrm{~cm}$ Whatman type filter paper, which was immediately placed inside the exposure chamber containing five Petri dishes (ensuring five replications). The following doses were applied: 2, 5, 10, and $20 \mu \mathrm{L}$ [29]. Ten insects were introduced to each Petri dish and one untreated chamber served as the control. Dead insects were counted daily for a period of 7 days.

\subsubsection{Ingestion toxicity.}

The soft wheat seeds used in this test were not treated chemically and were stored in controlled conditions (T: $25^{\circ} \mathrm{C}, \mathrm{H}: 75 \%$ ). For each test, $1 \mathrm{~mL}$ of each concentration $2,5,10$ and $20 \mu \mathrm{L} \mathrm{EO} / \mathrm{mL}$ of acetone was applied to $20 \mathrm{~g}$ of seeds, corresponding to the following concentrations: $0.1,0.25,0,5$ and $1 \mu \mathrm{L} / \mathrm{g}$ respectively. These treated seeds were placed in Petri dishes and thoroughly mixed. The trials were repeated three times for each dose. After 5 minutes, the time necessary to allow the solvent to evaporate, ten adult insects of each species were placed in all the Petri dishes. The blank obtained only $1 \mathrm{~mL}$ of acetone. Dead insects were counted daily for a period of 7days.

\subsection{Statistical analysis.}

The number of dead insects was counted every 24 hours. Mortalities in the treated boxes (MB) were expressed according to Abbott's [30]. The formula for corrected mortality (Mc), taking into account the natural mortality observed in the control boxes (Mt) according to the following formula:

$$
M c=(M o-M t) /(100-M t) * 100
$$

To estimate the $\mathrm{LC}_{50}$ and $\mathrm{LT}_{50}$ using EO (The concentration and time of treatments necessary for the EO to kill $50 \%$ of the insects tested), regression lines were constructed by plotting the corrected mortality rate (given in Probits) as a function of the treatment concentration (taken as a log) [31]. The results obtained were the subject of an analysis of variance (ANOVA) to detect whether or not there were differences between the treatments at the $5 \%$ threshold.

\section{Results}

\subsection{Characterization of the essential oil of the aerial parts.}

The hydrodistillation of the dried aerials parts of $P$. incisa gave a brownish-yellow oil with an aromatic, fragrant odor. The oil yield was $0.40 \%$. The GC-MS analysis is based on the Nist-2014 library. Sixty-six compounds were identified, representing $89.4 \%$ of the total oil 
(Table 1). The main components were $\alpha$-ocimene (15.17\%), $\tau$-cadinol $(6.79 \%), \alpha$-cadinol (4.51\%), alloaromadendrene $(4.45 \%) \delta$ - cadinene, $(+)$ - (4.13\%) (Figure 1$)$.<smiles>C=CC(C)=CCCC(=C)C</smiles>

$\alpha$-Ocimene

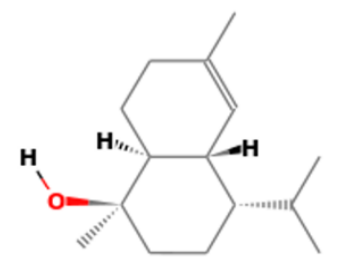

$\tau$-Cadinol

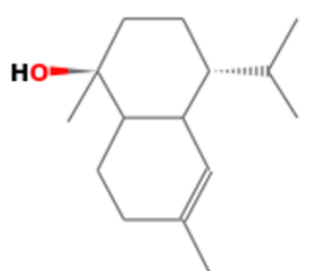

$\alpha$-Cadinol

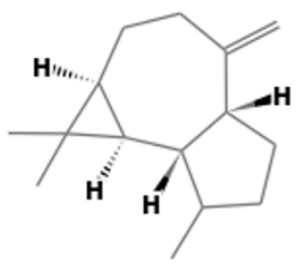

Alloaromadendrene

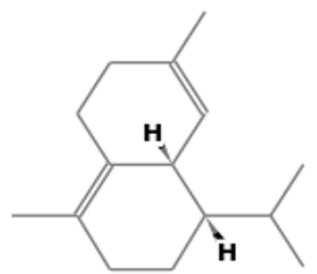

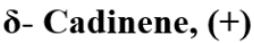

Figure 1. Chemical structure of selected major compounds identified in Pulicaria incisa essential oil.

\subsection{Repellent activity tests.}

Repellency test results are shown in Figure 2. The EO of $P$. incisa showed significant pest repellent activity to $S$. oryzae and $T$. castaneum. Oil was repellent even at low concentrations. Repellent action was highly dependent upon oil concentration and exposure time. The maximum activity (100\% repellency) was observed at the highest concentration $\left(0.157 \mu \mathrm{L} / \mathrm{cm}^{2}\right)$ and $\left(0.314 \mu \mathrm{L} / \mathrm{cm}^{2}\right)$ after 4 days for $S$. oryzae and 5 days for $T$. castaneum. The mortality rate varied considerably depending on the time of exposure and the concentrations of the EO tested. Malathion insecticide also showed significant results. It caused $100 \%$ mortality in $S$. oryzae and $90 \%$ in T. castaneum.

Sitophilus oryzae (L.)

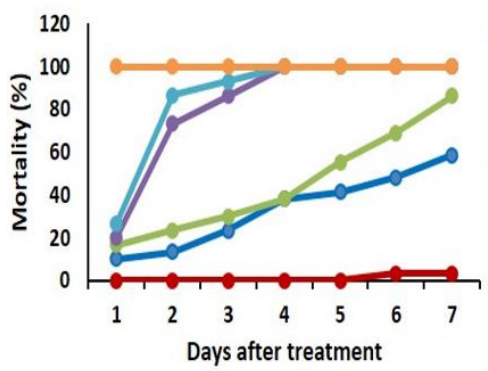

Tribolium castaneum (Herbst.)

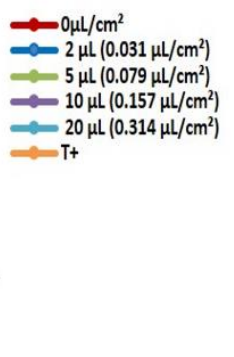

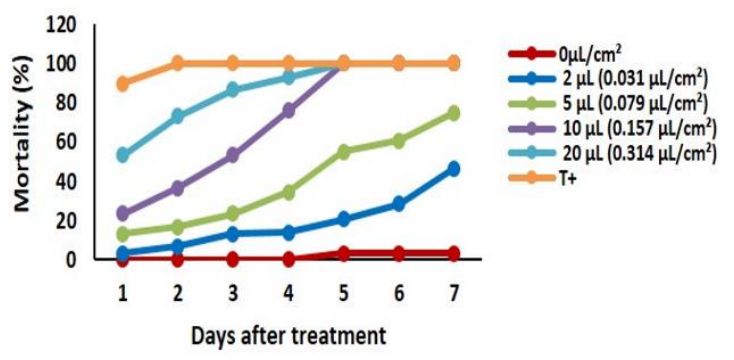

Figure 2. Mortality of $S$. oryzae and $T$. castaneum exposed to different concentrations of $P$. incisa essential oil by repellency test.

Table 1. Chemical composition of $P$. incisa aerial parts essential oil.

\begin{tabular}{c|c|c|c} 
Peak No. & Compounds & $\boldsymbol{t}_{\boldsymbol{R}(\boldsymbol{m i n})}$ & $\boldsymbol{P}$.incisa $(\boldsymbol{\%})$ \\
\hline $\mathbf{1}$ & Furfural & 0.655 & 0.33 \\
\hline $\mathbf{2}$ & o-Xylene & 0.773 & 3.41 \\
\hline $\mathbf{3}$ & Benzene, 1-ethyl-2-methyl- & 1.428 & 0.32 \\
\hline $\mathbf{4}$ & Hemimellitene & 1.503 & 0.89
\end{tabular}




\begin{tabular}{|c|c|c|c|}
\hline Peak No. & Compounds & $t_{R}(\min )$ & P.incisa $(\%)$ \\
\hline 5 & Mesitylene & 2.190 & 0.11 \\
\hline 6 & Benzeneacetaldehyde & 2.577 & 0.68 \\
\hline 7 & Benzene, 2-ethyl-1,4-dimethyl- & 2.856 & 0.33 \\
\hline 8 & Linalool & 3.650 & 0.55 \\
\hline 9 & Naphthalene & 4.488 & 0.17 \\
\hline 10 & $\alpha$-Terpineol & 4.842 & 0.42 \\
\hline 11 & 5-Octadecene, $(\mathrm{E})$ - & 5.067 & 0.50 \\
\hline 12 & 8,9-Dehydrothymol & 5.218 & 0.47 \\
\hline 13 & Coumaran & 5.626 & 0.38 \\
\hline 14 & dl-Perillaldehyde & 5.905 & 2.62 \\
\hline 15 & Anethole & 6.141 & 0.16 \\
\hline 16 & Indole & 6.238 & 0.14 \\
\hline 17 & o-Isopropylanisole & 6.527 & 1.24 \\
\hline 18 & 1, 1, 5-Trimethyl-1, 2-dihydronaphthalene & 6.860 & 0.19 \\
\hline 19 & 2H-1-Benzopyran-2-one, 3,4-dihydro-6-methyl- & 6.935 & 0.35 \\
\hline 20 & Eugenol & 7.107 & 2.02 \\
\hline 21 & $\alpha$-Copaene & 7.225 & 0.24 \\
\hline 22 & $\beta$-damascenone & 7.419 & 0.35 \\
\hline 23 & Methyl perillate & 7.612 & 0.75 \\
\hline 24 & 1-Tetradecene & 7.837 & 2.12 \\
\hline 25 & Methyleugenol & 7.987 & 0.51 \\
\hline 26 & Coumarin, 3,4-dihydro-4,5,7-trimethyl & 8.234 & 0.35 \\
\hline 27 & $\begin{array}{l}\text { Bicyclo[4.4.0]dec-1-ene, 2-isopropyl-5-methyl-9- } \\
\text { methylene- }\end{array}$ & 8.406 & 0.31 \\
\hline 28 & cis-Muurola-4(15),5-diene & 8.632 & 0.16 \\
\hline 29 & Valencene & 8.868 & 0.19 \\
\hline 30 & $\begin{array}{l}\text { Naphthalene, 1,2,4a,5,6,8a-hexahydro-4,7- } \\
\text { dimethyl-1-(1-methylethyl)- }\end{array}$ & 9.029 & 1.03 \\
\hline 31 & $\begin{array}{l}\text { Bicyclo[4.4.0]dec-1-ene, 2-isopropyl-5-methyl-9- } \\
\text { methylene- }\end{array}$ & 9.136 & 0.26 \\
\hline 32 & $\gamma$-Selinene & 9.308 & 0.26 \\
\hline 33 & Thymyl isobutyrate & 9.480 & 1.44 \\
\hline 34 & $\alpha$-Muurolene & 9.555 & 0.89 \\
\hline 35 & $\gamma$-Cadinene & 9.737 & 1.59 \\
\hline 36 & Longifolene & 9.855 & 1.42 \\
\hline 37 & $\delta$-Cadinene, $(+)-$ & 10.070 & 4.13 \\
\hline 38 & (+)-Calarene & 10.253 & 0.89 \\
\hline 39 & 3,5-Heptadienal, 2-ethylidene-6-methyl- & 10.564 & 1.22 \\
\hline 40 & Germacrene D-4-ol & 11.015 & 3.32 \\
\hline 41 & $\beta$-Caryophyllene & 11.230 & 0.92 \\
\hline 42 & Cyclooctene, 4-methylene-6-(1-propenylidene)- & 11.348 & 0.35 \\
\hline 43 & 2-Dodecen-4-yne, $(\mathrm{E})$ - & 11.723 & 1.22 \\
\hline 44 & Cetene & 12.185 & 2.42 \\
\hline 45 & $\begin{array}{l}\text { bicyclo } 5.2 .0 \text { nonane 2-methylene-4 } 8 \text { 8-trimethyl- } \\
\text { 4-vinyl- }\end{array}$ & 12.400 & 3.30 \\
\hline 46 & $\tau$-Cadinol & 12.625 & 6.79 \\
\hline 47 & $\alpha$-Cadinol & 12.904 & 4.51 \\
\hline 48 & Alloaromadendrene & 13.484 & 4.45 \\
\hline 49 & $\begin{array}{l}\text { 1-[3-(2,6,6-Trimethyl-cyclohex-2-enyl)-4,5- } \\
\text { dihydro-3H-pyrazol-4-yl]-ethanone }\end{array}$ & 14.354 & 2.53 \\
\hline 50 & Oplopanone & 14.665 & 0.82 \\
\hline 51 & Cyperotundone & 14.901 & 0.55 \\
\hline 52 & Octanal, 2-(phenylmethylene)- & 15.223 & 0.57 \\
\hline 53 & Isoaromadendrene epoxide & 15.610 & 1.80 \\
\hline 54 & Z-3-Hexadecen-7-yne & 15.749 & 2.15 \\
\hline 55 & Caryophyllene Oxide & 16.232 & 0.36 \\
\hline 56 & $\alpha$-Ocimene & 17.080 & 15.17 \\
\hline 57 & 2-Pentadecanone, 6,10,14-trimethyl & 18.014 & 1.07 \\
\hline
\end{tabular}




\begin{tabular}{c|c|c|c} 
Peak No. & Compounds & $\boldsymbol{t}_{\boldsymbol{R}(\boldsymbol{m i n})}$ & $\boldsymbol{P} \mathbf{. i n c i s a}(\boldsymbol{\%})$ \\
\hline $\mathbf{5 8}$ & Cedran-diol, (8S, 14)- & 18.873 & 0.13 \\
\hline $\mathbf{5 9}$ & Longiverbenone & 19.399 & 0.95 \\
\hline $\mathbf{6 0}$ & Heptadecane & 20.784 & 0.31 \\
\hline $\mathbf{6 1}$ & (R)-(-)-14-Methyl-8-hexadecyn-1-ol & 24.788 & 0.17 \\
\hline $\mathbf{6 2}$ & 9-Nonadecene & 25.701 & 0.67 \\
\hline $\mathbf{6 3}$ & Eicosane & 25.840 & 0.50 \\
\hline $\mathbf{6 4}$ & 1-Nonadecene & 29.608 & 0.42 \\
\hline $\mathbf{6 5}$ & Heneicosane & 31.594 & 0.49 \\
\hline $\mathbf{6 6}$ & Tetracosane & 35.094 & 0.25 \\
\hline & Monoterpenes hydrocarbons & 15.17 \\
\hline & Oxygenated monoterpenes & 6.75 \\
\hline & Sesquiterpenes hydrocarbons & 19.64 \\
\hline & Oxygenated sesquiterpenes & 16.31 \\
\hline & Others oxygenated compound & 5.15 \\
\hline & Benzene derivative & & 9.61 \\
\hline & Coumarin derivative & & 0.7 \\
\hline & Norisoprenoids & & 0.35 \\
\hline & Others & & $\mathbf{8 9 . 4}$
\end{tabular}

$t_{R:}$ Retention Time.

\subsection{Fumigant toxicity.}

The results revealed that all EO concentrations induced significant mortality compared to the control (without treatment) for both insect species. Insect mortality was directly proportional to the concentration and duration of exposure (Figure 3). During the 7 th day after the exposure period, all other concentrations tested $(2,5,10$, and $20 \mu \mathrm{L} / \mathrm{L}$ of air) recorded mortality of more than $50 \%$. The concentration of $20 \mu \mathrm{L} / \mathrm{L}$ of air of $P$. incisa resulted in $100 \%$ mortality of $S$. oryzae and $T$. castaneum after 3 and 4 days of exposure, respectively. The mortality recorded in the positive control (fumigant of aluminum phosphide) was less effective after the entire duration of treatment for the two insects.

Sitophilus oryzae (L.)

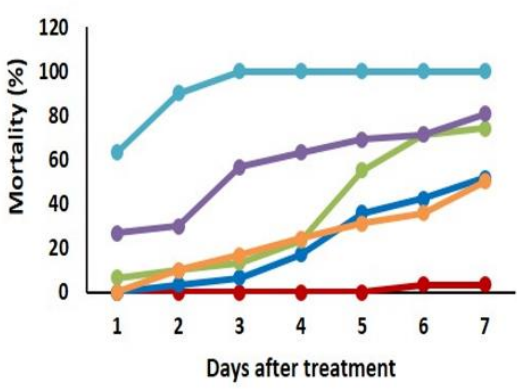

Tribolium castaneum (Herbst.)

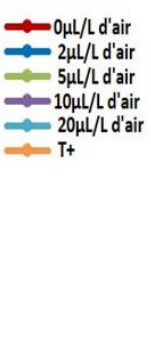

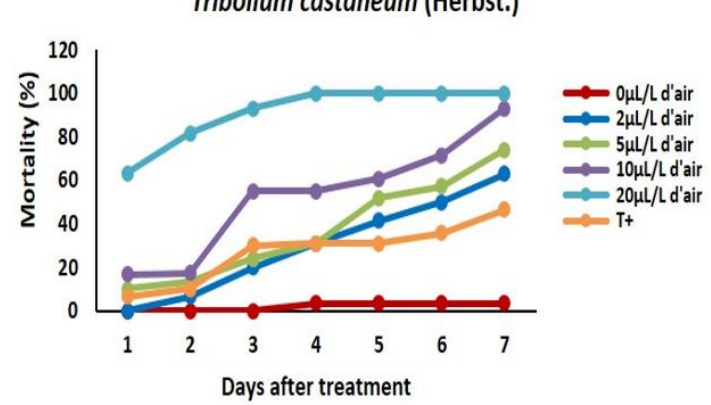

Figure 3. Mortality of $S$. oryzae and $T$. castaneum exposed to different concentrations of $P$.incisa essential oil by fumigant test.

\subsection{Ingestion activity tests.}

The results of toxicity by ingestion of P. incisa EO showed that all the tested concentrations induced significant mortality compared to the control for the two species of insect pests. Figure 4 shows the percentage of adult mortality of $S$. oryzae and $T$. castaneum, which varied with different EO concentrations and exposure time. The results indicate that the concentrations of $0.5 \mu \mathrm{L} / \mathrm{g}$ and $1 \mu \mathrm{L} / \mathrm{g}$ induce total destruction of both insects. Therefore, the 
weevil $S$. oryzae was found to be more sensitive to oil exposure than $T$. castaneum. However, the mortality recorded in the positive control dishes treated with Malathion is more effective, inducing total mortality after 2 days of treatment for the two insects.

Sitophilus oryzae (L.)

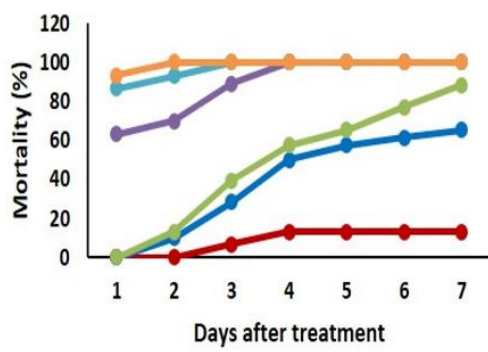

Tribolium castaneum (Herbst)

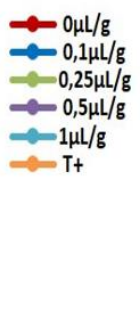

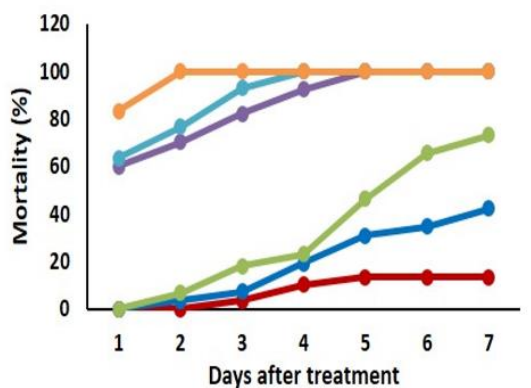

Figure 4. Mortality of $S$. oryzae and $T$. castaneum exposed to different concentrations of $P$.incisa essential oil by ingestion test.

\section{Discussion}

Pulicaria incisa is a wild-growing plant in Morocco. The yield of the EO extracted from the aerial parts of this plant was $0.50 \%$. Our results agree with previous studies carried out on the same species previously studied for other biological activities. A similar yield of $0.50 \%$ was obtained by Chaib et al. [32] after hydrodistillation of aerial parts of the Algerian plant. The OEs of Pulicaria incisa sub. growing wild in Egypt has a pleasant aroma with an average yield of $0.66 \%$ [33]. Another study carried out on Pulicaria vulgaris growing in Tunisia gave essential yellow-colored oils and a yield of $0.05 \%$ [22]. Authors reported that the genus Pulicaria yields relatively moderate quantities of EO. To the best of our knowledge, this is the first report on the chemical composition of the EO produced from the aerial parts a of Pulicaria incisa grown in Morocco. We used gas chromatography-mass spectrometry (GCMS) for the analysis of the EO. A total of sixty-six compounds have been identified. This oil was rich in sesquiterpenes hydrocarbons (19.64\%), oxygenated sesquiterpenes $(16.31 \%)$ and monoterpenes hydrocarbons (15.17\%). Other similar studies on the genus Pulicaria revealed mainly the presence of oxygenated monoterpenes (64.0\%) and aromatic derivatives $(18.8 \%)$ [34], sesquiterpene lactones [35,36], and caryophyllene derivatives [37,38]. In addition, the EO of Pulicaria incisa, growing in Egypt, was characterized by the high content of carvotanacetone $(66.01 \%)$ and chrysanthenone (13.26\%) [33]. Our results and those previously reported clearly indicate variations in chemical composition, which depend on the plant origin of the EO. Moreover, most Pilucaria species are considered good sources of bioactive components having a broad spectrum of biological activities.

In the current research, the potential of repellency, fumigant and ingestion toxicity of $P$. incisa EO was examined. According to the doses, the results of the statistical analysis of EO reveal the existence of a significant difference between the percentage of mortality in the control batches and those treated with EO, which explains why these products show an insecticidal effect on the two pests studied. For repellent bioassay, both insects were susceptible to EO and both adults were repelled at all concentrations. The probit analysis, $\mathrm{LC}_{50}$ values (lethal concentration for $50 \%$ mortality) of $P$. incisa EO against $S$. oryzae and $T$. castaneum, varied between $15.49-1.73 \mu \mathrm{L} / \mathrm{cm}^{2}$ and $20.89-2.29 \mu \mathrm{L} / \mathrm{cm}^{2}$ respectively for different 
observation (Table 2). Lethal time (LT50), to kill $50 \%$ of S. oryzae adults, varied between 6.3 0.8 days and 11.5 - 1.2 days for T. castaneum for different oil concentrations tested (Table 3 ).

According to the results of the fumigation test, the adults of $S$. oryzae and $T$. castaneum were susceptible to the $P$. incisa EO with LC50 values varied between $16.21-2.08$ and 18.62 $2.51 \mu \mathrm{L} / \mathrm{L}$ air. The $\mathrm{LT}_{50}$ values for $S$. oryzae is ranged from 6.2 - 0.7 days and $7.4-0.9$ days for $T$. castaneum. The susceptibility of $S$. oryzae and $T$. castaneum to plant EO was illustrated in the previous studies that support the results of the present study. For example, the contact and fumigation bioactivity of Tagetes terniflora $\mathrm{EO}$ against $T$. castaneum and $S$. oryzae, has been shown to be toxic by contact for $S$. oryzae but less toxic for T. castaneum [39]. On the other hand, strong toxicity was observed with Foeniculum vulgar Mill and Pimpinella anisum L. EOs against $T$. castaneum, which recorded $\mathrm{LC}_{50}$ of 91.28 and $43.75 \mu \mathrm{L} / \mathrm{L}$ of air after 24 hours respectively[40]. Similar results were obtained using Mentha microphylla oil by the fumigant test, which exhibited the highest insecticidal activity among Egyptian oils tested against $S$. oryzae and $T$. castaneum with $\mathrm{LC}_{50}$ values of $0.21 \mu \mathrm{L} / \mathrm{L} 4.51 \mu \mathrm{L} / \mathrm{L}$ respectively [41]. The EO of the Iranian wild plant Perovskia abrotanoides has a similar effect on these two insects, with the lowest concentration ( $32 \mathrm{~mL} / \mathrm{L}$ of air) causing $100 \%$ mortality $S$. oryzae and T. castaneum After 15 and 8 hours of exposure [42].

The EOs of certain plants of Myrtaceae growing in Australia and Artemisia sieberi from Iran has been reported to possess fumigant toxicity against these two adult insects $[43,44]$. Another study showed the effect of Echinacea purpurea EO from the Asteraceae family by different methods against $S$. granarius and $T$. castaneum, this oil caused a $99.59 \%$ mortality of $S$. granarius after 72 hours and a strong repellent activity of $98 \%$ against $T$. castaneum at a dose of 1\% [45]. Amini et al. [46] studied four Nepeta L. species against the rice weevil, They revealed that Nepeta glomerulosa exhibited the highest fumigant activity with LC $\mathrm{C}_{50}$ of 124.318 $\mu \mathrm{L} /$ Lair, while Nepeta binaloudensis and Nepeta cataria showed an effect $100 \%$ repellent at a dose of $25 \mu \mathrm{L} / 30 \mathrm{~cm}^{2}$ against $S$. oryzae.

The interaction between the two insects and the EO of $P$. incisa also lasted for seven days by ingestion bioassay. The $\mathrm{LC}_{50}$ calculated within $S$. oryzae and $T$. castaneum were of the order of $12.59-1.51 \mu \mathrm{L} / \mathrm{g}$ and $14.12-2.39 \mu \mathrm{L} / \mathrm{g}$, respectively. The $\mathrm{LT}_{50}$ values for $S$. oryzae is ranged from 4.7 - 0.8 days and 8.5 - 0.9 days for T. castaneum. Furthermore, as the EO concentration increased, the LT50 values decreased and in all cases, increased susceptibility of both insects was directly related to oil concentration and exposure time.

In the present study, $P$ incisa EO was extremely toxic against the rice weevil and the red flour beetle. A possible explanation for these results is again linked to the richness of the genus Pulicaria inactive compounds. $\alpha$-Ocimene has been found to be the main component of EO. But the toxicity may be due to the synergistic effect of different components. Our essential oil was composed of complex mixtures (sesquiterpene hydrocarbons, oxygenated sesquiterpenes and monoterpene hydrocarbons), which may be the origin of this insecticidal activity. These compounds are often present as major components of EOs in aromatic plants of the Asteraceae family. EOs can cause direct mortality and drastically reduce pest fertility, longevity, and vitality $[47,48]$. Based on these various facts, herbal medicines can play an important role as safe botanical insecticides against stock pests.

\section{Conclusions}

The data presented in this study demonstrate the insecticidal power of the P. incisa plant growing wild in the region of Beni Mellal-Khenifra, Morocco. Farmers use this plant to 
preserve the quality of their seeds. Our results reveal the insecticidal effect of $P$. incisa against $S$. oryzae and $T$. castaneum by different methods (ingestion, repulsion and fumigation), determined by us is the first to be published. This work clearly justifies the interest in the effectiveness of Moroccan essential oils, which respond to global interest by the development of substances based on plant products as natural insecticides against pests of stored products. The use of botanical insecticides based on our selected EO can thus become an important alternative. However, further studies are needed to assess the biological efficacy in the field, the formulation feasibility of these products and the verification on a broad spectrum of insect pests.

\section{Funding}

This research did not receive any specific grant from funding agencies in the public, commercial, or not-for-profit sectors.

\section{Acknowledgments}

This work was supported by the funds of the National Institute of Agronomic Research Meknes, Morocco.

\section{Conflicts of Interest}

The authors declare that there was no conflict of interest.

\section{References}

1. Dissanayaka, D.M.S.K.; Sammani, A.M.P.; Wijayaratne, L.K.W. Food oils as kairomones for trapping Tribolium castaneum (Herbst)(Coleoptera: Tenebrionidae) adults. Journal of Stored Products Research 2018, 79, 83-88, https://doi.org/10.1016/j.jspr.2018.09.005.

2. Attia, M. A.; Wahba, T.F.; Shaarawy, N.; Moustafa, F.I.; Guedes, R.N.C.; Dewer, Y. Stored grain pest prevalence and insecticide resistance in Egyptian populations of the red flour beetle Tribolium castaneum (Herbst) and the rice weevil Sitophilus oryzae (L.). Journal of Stored Products Research 2020, 87, 101611, https://doi.org/10.1016/j.jspr.2020.101611.

3. Food and Agriculture Organisation (FAO). Tackling COVID-19's effect on food supply chains in Africa. 2020. Available online: http://www.fao.org/africa/news/detail-news/en/c/1272643/ (accessed 10 January 2021).

4. Brito, V.D.; Achimón, F.; Pizzolitto, R.P.; Sánchez, A.R.; Torres, E.A.G.; Zygadlo, J.A.; Zunino, M.P. An alternative to reduce the use of the synthetic insecticide against the maize weevil Sitophilus zeamais through the synergistic action of Pimenta racemosa and Citrus sinensis essential oils with chlorpyrifos. Journal of Pest Science 2021, 94, 409-421.

5. Cruz, J.F.; Hounhouigan, J.D.; Fleurat-Lessard, F.; Troude, F. Grain conservation after harvest. 2016, Editions Quae.

6. Ahmad, F.; Iqbal, N.; Zaka, S.M.; Qureshi, M.K.; Saeed, Q.; Khan, K.A.; Awar, M.B. Comparative insecticidal activity of different plant materials from six common plant species against Tribolium castaneum (Herbst)(Coleoptera: Tenebrionidae). Saudi journal of biological sciences 2019, 26, 1804-1808, https://doi.org/10.1016/j.sjbs.2018.02.018.

7. Upadhyay, N.; Dwivedy, A. K.; Kumar, M.; Prakash, B.; Dubey, N. K. Essential oils as eco-friendly alternatives to synthetic pesticides for the control of Tribolium castaneum (Herbst)(Coleoptera: Tenebrionidae). Journal of Essential Oil Bearing Plants 2018,21, 282-297, https://doi.org/10.1080/0972060X.2018.1459875.

8. Cao, J.Q.; Pang, X.; Guo, S.S.; Wang, Y.; Geng, Z.F.; Sang, Y.L.; Du, S.S. Pinene-rich essential oils from Haplophyllum dauricum (L.). Don display anti-insect activity on two stored-product insects. International Biodeterioration \& Biodegradation 2019, 140, 1-8, https://doi.org/10.1016/j.ibiod.2019.03.007. 
9. Saad, M.M.; El-Deeb, D.A.; Abdelgaleil, S. A. Insecticidal potential and repellent and biochemical effects of phenylpropenes and monoterpenes on the red flour beetle, Tribolium castaneum Herbst. Environmental Science and Pollution Research 2019, 26, 6801-6810, https://doi.org/10.1007/s11356-019-04151-z.

10. Pavela, R.; Maggi, F.; Lupidi, G.; Mbuntcha, H.; Woguem, V.; Womeni, H.M.; Benelli, G. Clausena anisata and Dysphania ambrosioides essential oils: from ethno-medicine to modern uses as effective insecticides. Environmental Science and Pollution Research 2018, 25, 10493-10503, https://doi.org/10.1007/s11356-0170267-9.

11. Rajkumar, V.; Gunasekaran, C.; Christy, I.K.; Dharmaraj, J.; Chinnaraj, P.; Paul, C.A. Toxicity, antifeedant and biochemical efficacy of Mentha piperita L. essential oil and their major constituents against stored grain $\begin{array}{lllll}\text { pest. Pesticide biochemistry } & \text { and }\end{array}$ https://doi.org/10.1016/j.pestbp.2019.02.016.

12. Adak, T.; Barik, N.; Patil, N.B.; Gadratagi, B.G.; Annamalai, M.; Mukherjee, A.K.; Rath, P.C. Nanoemulsion of eucalyptus oil: An alternative to synthetic pesticides against two major storage insects (Sitophilus oryzae (L.) and Tribolium castaneum (Herbst)) of rice. Industrial crops and products 2020, 143, 111849, https://doi.org/10.1016/j.indcrop.2019.111849.

13. Ndomo, A. F.; Tapondjou, A.L.; Tendonkeng, F.; Tchouanguep, F.M. Evaluation of the insecticidal properties of the leaves of Callistemon viminalis (Myrtaceae) against adults of Acanthoscelides obtectus (Say)(Coleoptera; Bruchidae). Tropicultura 2009, 27, 137-143

14. Reyes, E. I.; Farias, E.S.; Silva, E.M.; Filomeno, C.A.; Plata, M.A.; Picanço, M.C., Barbosa, L. C. Eucalyptus resinifera essential oils have fumigant and repellent action against Hypothenemus hampei. Crop Protection 2019, 116, 49-55, https://doi.org/10.1016/j.cropro.2018.09.018.

15. Zimmermann, R. C.; De Carvalho Aragão, C. E.; De Araújo, P. J. P.; Benatto, A.; Chaaban, A.; Martins, C.E.N.; Zawadneak, M.A. Insecticide activity and toxicity of essential oils against two stored-product insects. Crop Protection 2021, 105575, https://doi.org/10.1016/j.cropro.2021.105575.

16. Jevremović, S.; Lazarević, J.; Kostić, M.; Krnjajić, S.; Ugrenović, V.; Radonjić, A.; Kostić, I. Contact application of Lamiaceae botanicals reduces bean weevil infestation in stored beans. Archives of Biological Sciences 2019, 71, 665-676.

17. Bagade, R. P.; Jadhav, A.D.; Chavan, R.V. Toxicity and repellency of four plant essential oils against Tribolium castaneum (Herbst)(Coleoptera: Tenebrionidae). International Journal of Tropical Insect Science 2020, 1-8, https://doi.org/10.1007/s42690-020-00348-9.

18. Zhang, P.; Qin, D.; Chen, J.; Zhang, Z. Plants in the genus Tephrosia: Valuable resources for botanical insecticides. Insects 2020, 11, 721, https://doi.org/10.3390/insects11100721.

19. Bakkali, F.; Averbeck, S.; Averbeck, D.; Idaomar, M. Biological effects of essential oils - a review. Food Chem. Toxicol 2008, 46, 446-475, https://doi.org/10.1016/j.fct.2007.09.106.

20. Babarinde, S.A.; Akinyemi, A.O.; Usman, L.A.; Odewole, A.F.; Sangodele, A.O.; Iyiola, O.O.; Olalere, O.D. Toxicity and repellency of Hoslundia opposita Vahl (Lamiaceae) leaves essential oil against rust-red flour beetle, Tribolium castaneum Herbst (Coleoptera: Tenebrionidae). Nat Prod Res 2014, 28, 365-371, https://doi.org/10.1080/14786419.2013.866115.

21. Mohammed, A.B.; Yagi, S.; Tzanova, T.; Schohn, H.; Abdelgadir, H.; Stefanucci, A.; Mollica, A.; Mahomoodally, M.F.; Adlan, T.A.; Zengin, G. Chemical profile, antiproliferative, antioxidant and enzyme inhibition activities of Ocimum basilicum L. and Pulicaria undulata (L.) CA Mey. grown in Sudan. South African Journal of Botany 2020, 132, 403-409, https://doi.org/10.1016/j.sajb.2020.06.006.

22. Zardi-Bergaoui, A.; Jelassi, A.; Daami-Remadi, M.; Harzallah-Skhiri, F.; Flamini, G.; Ascrizzi, R.; Ben Jannet, H. Chemical composition and bioactivities of essential oils from Pulicaria vulgaris subsp. dentata (Sm.) Batt. growing in Tunisia. Journal of Essential Oil Research 2020,32, 111-120, https://doi.org/10.1080/10412905.2019.1698468.

23. El-Sabagh, O.A.; El-Toumy, S.A.; Mounir, R.; Farag, M.A.; Mahrous, E.A. Metabolite profiles of Pulicaria crispa and Pulicaria incisa in relation to their in-vitro/in-vivo antioxidant activity and hepatoprotective effect: A comparative mass spectrometry-based metabolomics. Journal of Pharmaceutical and Biomedical Analysis 2020, 113804, https://doi.org/10.1016/j.jpba.2020.113804.

24. El-Shahaby, O.; El-Zayat, M.; Rabei, R.; Aldesuquy, H.S. Phytochemical constituents, antioxidant activity and antimicrobial potential of Pulicaria incisa (lam.) DC as a folk medicinal plant. Progress in Chemical and Biochemical Research 2019, 2, 222-227. 
25. Ross, S. A.; El-Sayed, K. A.; El-Sohly, M.A.; Hamann, M.T.; Abdel-Halim, O.B.; Ahmed, A. F.; Ahmed, M.M. Phytochemical Analysis of Geigeria alata and Francoeuria crispa essential oils. Planta Medica 1997, 63, 479-482, https://doi.org/10.1055/s-2006-957743.

26. Dubaie, A.S.; El-Khulaidi, A.A. Medicinal and aromatic plants in Yemen, deployment-components of effective-uses. Ebadi Center for studies and Publishing Sana'a- Yemen, 2005, 127.

27. Govindaraju, S.; Indra Arulselvi, P. In vitro Antioxidant, Antibacterial Activity of C. aromaticus Essential Oil against Multidrug Resistant (MDR) Urinary Tract Infected Pathogens. International Journal of Pharmacognosy and Phytochemical Research 2014, 6, 996-1001.

28. McDonald, L. L.; Guy, R.H.; Speirs, R.D. Preliminary evaluation of new candidate materials as toxicants, repellents and attractants against stored-product insects. Marketing Research Report 1970, 882.

29. El Idrissi, M.; Elhourri, M.; Amechrouq, A.; Boughdad, A. Study of the insecticidal activity of the essential oil of Dysphania ambrosioides L. (Chenopodiaceae) on Sitophilus oryzae (Coleoptera: Curculionidae). Journal of Materials and Environmental Science 2014, 5(4), 989-994.

30. Abbott, W.S. A method of computing the effectiveness of an insecticide. J. Econ. Entomol 1925, 18: 265267.

31. Finney, D.J. Probit analysis, 3rd edn. Cambridge University Press. 1971, London.

32. Chaib, F.; Allali, H.; Bennaceur, M.; Flamini, G. Chemical composition and antimicrobial activity of essential oils from the aerial parts of Asteriscus graveolens (Forssk.) Less. and Pulicaria incisa (Lam.) DC. : Two Asteraceae herbs growing wild in the Hoggar. Chemistry \& biodiversity 2017, 14, e1700092.

33. Shahat, E. A.; Bakr, R.O.; Eldahshan, O.A.; Ayoub, N.A. Chemical composition and biological activities of the essential oil from leaves and flowers of Pulicaria incisa sub. candolleana (Family Asteraceae). Chemistry \& Biodiversity 2017, 14, e1600156.

34. Mustafa, A.M.; Eldahmy, S.I.; Caprioli, G.; Bramucci, M.; Quassinti, L.; Lupidi, G.; Maggi, F. Chemical composition and biological activities of the essential oil from Pulicaria undulata (L.) CA Mey. Growing wild in Egypt. Natural product research 2020, 34, 2358-2362.

35. Miller, A.G.; Morris, M. Plants of Dhofar. The southern region of Oman traditional, economic and medicinal uses. 1988, Muscat.

36. Wink, M. Evolution of secondary metabolites from an ecological and molecular phylogenetic perspective. Phytochemistry 2003, 64: 3-19.

37. Nanjo, F.; Goto, K.; Seto, R.; Suzuki, M.; Sakai, M.; Hara, Y. Scavenging effects of tea catechins and their derivatives on 1, 1-diphenyl-2-picrylhydrazyl radical. Free Radical Biology and Medicine 1996, 21, 895-902.

38. Javanmardi, J.; Stushnoff, C.; Locke, E.; Vivanco, J. M. Antioxidant activity and total phenolic content of Iranian Ocimum accessions. Food chemistry 2003, 83, 547-550, https://doi.org/10.1016/08915849(96)00237-7.

39. Stefanazzi, N.; Stadler, T.; Ferrero, A. Composition and toxic, repellent and feeding deterrent activity of essential oils against the stored-grain pests Tribolium castaneum (Coleoptera: Tenebrionidae) and Sitophilus oryzae (Coleoptera: Curculionidae). Pest Management Science 2011,67, 639-646, https://doi.org/0.1002/ps.2102.

40. Amini, S.; Tajabadi, F.; Khani, M.; Labbafi, M.R.; Tavakoli, M. Identification of the seed essential oil composition of four apiaceae species and comparison of their biological effects on Sitophilus oryzae L. and Tribolium castaneum (Herbst.). Journal of Medicinal Plants 2018, 17, 68-76.

41. Mohamed, M.I.; Abdelgaleil, S.A. Chemical composition and insecticidal potential of essential oils from Egyptian plants against Sitophilus oryzae (L.)(Coleoptera: Curculionidae) and Tribolium castaneum (Herbst)(Coleoptera: Tenebrionidae). Applied Entomology and Zoology 2008, 43, 599-607.

42. Arabi, F.; Moharramipour, S.; Sefidkon, F. Chemical composition and insecticidal activity of essential oil from Perovskia abrotanoides (Lamiaceae) against Sitophilus oryzae (Coleoptera: Curculionidae) and Tribolium castaneum (Coleoptera: Tenebrionidae). International Journal of Tropical Insect Science 2008, 28, 144-150, https://doi.org/10.1017/S1742758408079861.

43. Lee, B.H.; Annis, P.C.; Tumaalii, F.A.; Choi, W.S. Fumigant toxicity of essential oils from the Myrtaceae family and 1,8-cineole against 3 major stored-grain insects. J. Stored Prod. Res 2004, 40, 553-564, https://doi.org/10.1016/j.jspr.2003.09.001.

44. Negahban, M.; Moharramipour, S.; and Sefidkon, F. Fumigant toxicity of essential oil from Artemisia sieberi Besser against three stored product insects. J. Stored Prod. Res 2007, 43: 123-128, https://doi.org/10.1016/j.jspr.2006.02.002. 
45. Teke, M.A.; Mutlu, Ç. Insecticidal and behavioral effects of some plant essential oils against Sitophilus granarius L. and Tribolium castaneum (Herbst). Journal of Plant Diseases and Protection 2020, 1-11, https://doi.org/10.1007/s41348-020-00377-z.

46. Amini, S.; Nohooji, M.G.; Khani, M.; Labbafi, M.R.; Khalighi-Sigaroodi, F. Biological activity of some essential oil constituents in four Nepeta L. species against Sitophilus oryzae L. Biodiversitas Journal of Biological Diversity 2019, 20, 338-343, https://doi.org/10.13057/biodiv/d200205.

47. Pavela, R. Acute and synergistic effects of some monoterpenoid essential oil compounds on the house fly (Musca domestica L.). Journal of Essential Oil Bearing Plants 2008, 11, 451-459, https://doi.org/10.1080/0972060X.2008.10643653.

48. Hummelbrunner, L.A.; Isman, M.B. Acute, sublethal, antifeedant, and synergistic effects of monoterpenoid essential oil compounds on tobacco cutworm, Spodoptera litura (Lep., Noctuidae). J. Agric. Food Chem 2001, 49, 715-720, https://doi.org/10.1021/jf000749t. 